\title{
A comprehensive and in-depth analysis of the synthesis of advanced adsorbent materials
}

\author{
Francisco J. Osuna,${ }^{\dagger}$ Agustín Cota, ${ }^{\ddagger}$ Esperanza Pavón,${ }^{\dagger}$ María D. Alba ${ }^{\mathrm{a} \dagger}$ \\ ${ }^{\dagger}$ Instituto Ciencia de los Materiales de Sevilla (CSIC-US). Avda. Americo Vespucio, 49. 41092, Sevilla. \\ Spain. E-mail: alba@icmse.csic.es. \\ ¥ Centro de Investigación, Tecnología e Innovación de la Universidad de Sevilla. Avda. Reina Mercedes, 4b. \\ 41012, Sevilla. Spain
}

\begin{abstract}
Na-Mica-4, a synthetic fluorophlogopite, is an attractive adsorbent. However, the synthesis at large scale demands an economically prized, feasible scalable and sustainable synthesis method, which requires a deep knowledge of the influence of each synthesis step. A set of Na-Mica-4 were synthesised by methods that had one synthesis parameter as variable. The purity, crystallinity and heteroatoms distribution were analysed thorough Xray diffraction and nuclear magnetic resonance. The results shed a light on the main factors for the design of the final product and indicated that an environmental friendship synthesis could be possible.
\end{abstract}

\footnotetext{
a *Author to whom correspondence should be addressed. Tel.: +34 954489546. E-mail: alba@ $@$ icmse.csic.es.
} 


\section{Introduction}

Clay minerals are appropriate adsorbent materials that are used in applications such as catalysis, ion exchange and decontaminant. However, natural clays contain other minerals that are not adequate for those applications. For many important applications, pure synthetic clays are preferred.

Na-Mica-4, a synthetic fluorophlogopite, is an attractive adsorbent for its unique combination of high charge and swelling and cation exchange properties (Alba et al., 2006; Gregorkiewitz and Rausellcolom, 1987; Morikawa et al., 1982; Paulus et al., 1992). They have also shown preferential selectivity for harmful divalent and heavy metal cations, (Pavon et al., 2017) (Pavon et al., 2014a) hence they have been proposed as efficient adsorbents for removal of pollutants (Pazos et al., 2017) and immobilization of radioactive waste from water (Osuna et al., 2017). Moreover, their chemical and physical properties can easily be tuned by an appropriated synthesis design.

For the technical applications of those synthetic micas, feasible and economical scalable synthesis methods should be investigated. Moreover, an effective control of each synthesis step is crucial for an optimization of the synthesis parameters (Kloprogge et al., 1999; Zhang et al., 2010) such as chemical precursors (Gregorkiewitz and Rausellcolom, 1987; Kodama and Komarneni, 1999; Paulus et al., 1992), time (Alba et al., 2011) and temperature of reaction (Naranjo et al., 2015).

Synthesis procedure of clays has been refined and different starting materials were tested to achieve a cost efficient production (Gregorkiewitz and Rausellcolom, 1987; Kodama and Komarneni, 1999; Naranjo et al., 2014; Park et al., 2002a; Paulus et al., 1992). In fact, several 
studies have been conducted to find more cost-efficient aluminosilicate sources, such as fly ashes (Park et al., 2002a) or kaolinite (Kodama and Komarneni, 1999) for future large-scale applications. To elucidate the role of each synthesis step and parameters on the purity and structure of the Na-Mica-4, a strategy of synthesis has to be designed. A large-scale synthesis is possible as soon as all the synthesis steps are tuned.

Therefore, the goal of this research was to explore the effect of each synthesis parameters and steps on phase evolution and framework heteroatoms distribution to shed a light on an economical and sustainable method of synthesis that could be transferred to industrial sector.

\section{Materials and methods}

\subsection{Synthesis.}

For the synthesis of Na-Mica-4, the $\mathrm{NaCl}$ melt method was followed (Park et al., 2002a). The general procedure consists in the use of a powdered mixture with the following stoichiometry: $\mathrm{Si}: \mathrm{Al}: 1.5 \mathrm{Mg}: 2 \mathrm{Na}$. The starting materials were commercial oxides and salts $\left(\mathrm{SiO}_{2}, \mathrm{Al}(\mathrm{OH})_{3}, \mathrm{MgF}_{2}, \mathrm{NaCl}\right)$ and a set of natural clay minerals, series $\mathrm{C}$ and $\mathrm{D}$, (Table S1). Kaolinites, $\mathrm{KGa}-1 \mathrm{~b}$ and $\mathrm{KGa}-2$, were used as commercially provided and after miller.

The starting mixtures were grounded in an agate mortar, except sample B2, which was grounded in a planetary mill. The heating time and temperature was $900^{\circ} \mathrm{C}$ and $15 \mathrm{~h}$, except in the samples E2, E4, and E5, where the effect of time in the synthesis was evaluated and 30, 7.5 and $3.0 \mathrm{~h}$ were used. The reaction was held in Pt crucible for all the samples, except $\mathrm{E} 1$ and $\mathrm{E} 2-\mathrm{E} 5$, where $\mathrm{SiC}$ and $\mathrm{Al}_{2} \mathrm{O}_{3}$ crucible were used, respectively. The heated solids were cooled up to room temperature and washed with distiller water, except sample G2, which was washed with tap water. Finally, they were dried at room temperature. The changes on 
the synthesis steps, the details of the synthesis and the name of the samples are summarized in Table 1 and Table S2.

\subsection{Characterization.}

The mechanical grinding was performed using a Restch PM 200 planet miller with three tungsten carbide balls at $250 \mathrm{rpm}$ during $5 \mathrm{~min}$ for B2 sample and during $15 \mathrm{~min}$ for the kaolinites used as precursor of the synthesis of D1 and D2 samples.

The external surface was analysed by nitrogen adsorption isotherm at $77 \mathrm{~K}$ using a Micromeritics model ASAP 2010 and all samples were dried at $100{ }^{\circ} \mathrm{C}$ overnight under vacuum before the nitrogen sorption measurement. Those measurements allowed analysing the reactive surface of the starting materials.

The feature of the framework atoms bonds was studied by infrared (FTIR) spectroscopy. FTIR spectra were recorded in the range $4000-300 \mathrm{~cm}^{-1}$ by the Spectroscopy Service of the ICMS (CSIC-US, Seville, Spain), as KBr pellets, using a JASCO FT/IR-6200 IRT-5000 instrument.

In order to get information of the long-range structural transformations and the generation of the new crystalline phases, $\mathrm{x}$-ray diffraction (XRD) patterns were obtained at the X-ray laboratory (CITIUS, University of Seville, Spain) on a Bruker D8 Advance instrument equipped with a $\mathrm{Cu} \mathrm{K}_{\alpha}$ radiation source operating at $40 \mathrm{kV}$ and $30 \mathrm{~mA}$. Diffractograms were measured in the range $3-70^{\circ} 2 \theta$ with step time of $0.1 \mathrm{~s}$ and step size of $0.015^{\circ}$.

The changes of local environments of the framework heteroatoms during the synthesis process were analysed thorough nuclear magnetic resonance under magic angle spinning spectroscopy (MAS NMR). Single-pulse MAS NMR experiments were recorded on a Bruker 
AVANCE WB400 spectrometer equipped with a multinuclear probe. Powdered samples were packed in $3.2 \mathrm{~mm}$ zirconia rotors and spun at $10 \mathrm{kHz}$. The ${ }^{1} \mathrm{H}$ MAS NMR spectra were obtained using pulse widths of $2.25 \mu \mathrm{s}(\pi / 2)$ and a delay time of $5 \mathrm{~s} .{ }^{29} \mathrm{Si}$ MAS NMR spectra were acquired at a frequency of $79.49 \mathrm{MHz}$, pulse width of $2.7 \mu \mathrm{s}(\pi / 6)$ each $3 \mathrm{~s} .{ }^{27} \mathrm{Al}$ MAS NMR spectra were recorded at $104.26 \mathrm{MHz}$ with a pulse of $0.38 \mu \mathrm{s}(\pi / 20)$ and a delay time of $0.5 \mathrm{~s} .{ }^{23} \mathrm{Na}$ MAS NMR spectra were recorded at $105.84 \mathrm{MHz}$ with a pulse of $0.75 \mu \mathrm{s}(\pi / 12)$ and a delay time of $0.1 \mathrm{~s}$. The ${ }^{19} \mathrm{~F}$ MAS NMR spectra were obtained using typical a $\pi / 2$ pulse of $2.9 \mu \mathrm{s}$ and a pulse space of $2 \mathrm{~s}$. The chemical shift values were reported in ppm from tetramethylsilane for ${ }^{29} \mathrm{Si}$ and ${ }^{1} \mathrm{H}$, from $\mathrm{NaF}$ for ${ }^{19} \mathrm{~F}$ and from a $0.1 \mathrm{M} \mathrm{AlCl}_{3}$ and $\mathrm{NaCl}$ solution for ${ }^{27} \mathrm{Al}$ and ${ }^{23} \mathrm{Na}$, respectively. Spectra were simulated using the DMFIT software (Massiot et al., 2002) and Gaussian-Lorenztian ratio, position, linewidth and amplitude were the fitted parameters.

\section{Results and discussion}

\subsection{Effect of the precursor mixing}

3.1.1. Effect of stoichiometry. In order to identify the stoichiometry tolerance of the components for large-scale synthesis, two series of samples were synthesized and identified as series A on Table S2 and Table 1. Whereas sample A2 followed the stoichiometry proportion of the precursors for Na-Mica-4 (Park et al., 2002b), the sample A1 was synthesised with a deficiency of $2 \% \mathrm{Al}$ and $7 \% \mathrm{Mg}$. The rest of the synthesis process was identical (see Table 1).

X-ray diffractograms of the samples of series A (Fig. 1) showed patterns that corresponded to Na-Mica-4 (Naranjo et al., 2015) with a unique 001 reflection corresponding to a basal space of $12.1 \AA$ due to hydrated $\mathrm{Na}^{+}$(Alba et al., 2011). Additionally, in the XRD 
pattern of the sample $\mathrm{A} 1, \mathrm{Al}$ and $\mathrm{Mg}$ deficient starting mixture, small reflections of sodalite were observed. At long-range structural order, both stoichiometric compositions provided hydrated Na-Mica-4 but to ensure the efficiency of the Al framework incorporation and the Si-Al tetrahedral distribution, the ${ }^{29} \mathrm{Si}$ MAS NMR spectra were analysed. In both samples, the spectra (Fig. S1) consisted in a set of signals on the -70 to $-95 \mathrm{ppm}$ region due to $\mathrm{Q}^{3}(\mathrm{mAl})$ $(3 \leq \mathrm{m} \leq 0)$ mica environments (Alba et al., 2006) and $\mathrm{Q}^{4}(4 \mathrm{Al})$ from sodalite (Johnson et al., 2000). The area of each ${ }^{29} \mathrm{Si} \mathrm{Q}^{3}(\mathrm{mAl})$ signals (Fig. 2) were the same as previously reported for Na-Mica-4 (Alba et al., 2006). However, the proportion of the $\mathrm{Q}^{3}(3 \mathrm{Al})^{*}$ at ca. $-75 \mathrm{ppm}$, postulated as a Lowenstein rule violation (Pavon et al., 2014b), was slightly higher in sample A1, where the stoichiometric proportion was not followed.

The ${ }^{27}$ Al MAS-NMR spectrum of sample A2 (Fig. 3) showed a main signal at ca. 65 ppm due to the majority of $\mathrm{Al}$ in a tetrahedral coordination (Engelhardt and Michel, 1987) and an additional small signal at ca. $0 \mathrm{ppm}$ that was interpreted as aluminium in the octahedral sheet (Naranjo et al., 2014). The spectra of the sample A1 was similar but with a narrow and symmetric peak due to sodalite (Naranjo et al., 2014), in accordance with the presence of this phase in the XRD data.

Although the XRD data were compatible with hydrated interlayer sodium, the difference in the coordination sphere of the interlayer sodium can only be analysed by a ${ }^{23} \mathrm{Na}$ MAS-NMR spectroscopy (Fig. S2). The spectrum of sample A2 was characterized by a unique symmetrical signal centred at ca. $-7.5 \mathrm{ppm}$ compatible with the interlayer sodium in one-layer hydrated state (Naranjo et al., 2014). A similar signal was observed in sample A1, but the spectrum of this sample also showed a narrow peak at ca. $4 \mathrm{ppm}$ due to sodalite (Johnson et al., 2000) (Johnson et al., 2000) and involved the $5.8 \%$ of sodium. 
3.1.2. Effect of mixing. The effect of manual or mechanical mixing of the components in the yield and structure of the Na-Mica-4 was explored through the syntheses of the samples of series B (Table S2). In this synthesis, the precursor and mixture stoichiometry were similar to sample A2 but for sample B1, the components were mixed manually in an agate mortar and for sample B2, a double amount of components were mechanically mixed (Table 1).

X-ray diffractograms of the samples of series B (Fig. 1) showed similar patterns to those of sample A2 and, thus, compatible with pure Na-Mica-4 (Alba et al., 2006) with a unique 001 reflection corresponding to a basal space of $12.1 \AA$ of hydrate $\mathrm{Na}^{+}$(Alba et al., 2006). The ${ }^{29}$ Si MAS NMR spectra (Fig. S1) also consisted in a set of signals on the -70 to $-95 \mathrm{ppm}$ region due to $\mathrm{Q}^{3}(\mathrm{mAl})(3 \leq \mathrm{m} \leq 0)$ mica environments (Alba et al., 2006). However, the area of each ${ }^{29} \mathrm{Si} \mathrm{Q}^{3}(\mathrm{mAl})$ signal (Fig. 2) was affected by the mixing procedure. Whereas the area distribution in manual ground samples (sample B1) was similar to that of sample $\mathrm{A} 2$, the mechanical grinding favoured the $\mathrm{Q}^{3}(3 \mathrm{Al})$ environment and the proportion of the $\mathrm{Q}^{3}(3 \mathrm{Al})^{*}$ at ca. $-75 \mathrm{ppm}$, postulated as a Lowenstein rule violation (Pavon et al., 2014b), was slightly higher in sample B2. From a thermodynamical point of view, the Al-O-Al bonding is less favoured than Al-O-Si (Bell et al., 1992), however, the mechanical grinding should provide the energy necessary to favour them.

The ${ }^{27} \mathrm{Al}$ MAS-NMR spectra of series B samples (Fig. 3) were similar to that of sample A2, pure Na-Mica-4, with the main signal at ca. $65 \mathrm{ppm}$ with a majority of $\mathrm{Al}$ in a tetrahedral coordination (Engelhardt and Michel, 1987), and an additional small signal at ca. 0 ppm that was interpreted as aluminium in octahedral sheet (Alba et al., 2006). Those spectra didn't reveal the appearance of the ${ }^{27} \mathrm{Al}$ signal of sodalite. 
The ${ }^{23} \mathrm{Na}$ MAS NMR spectra of both samples (Fig. S2) were characterized by a unique symmetrical signal centred at ca. $-7.5 \mathrm{ppm}$ compatible with interlayer sodium in onelayer hydrated state (Laperche et al., 1990).

3.1.3. Effect of the chemical source. The potential use of natural and economical chemical sources was analysed thorough the series C and D (Table 1 and Table S2).

X-ray diffractograms of the samples of series C (Fig. 4) showed similar patterns to those of sample A2 and, thus, compatible with Na-Mica-4 (Alba et al., 2006) with a unique 001 reflection corresponding to a basal space of $12.1 \AA$ from interlayer hydrate $\mathrm{Na}^{+}$(Alba et al., 2011). The exception was the XRD pattern of sample C3, synthesised from the commercial kaolinite, which corresponded to a dehydrated Mica (PDF 00-054-1026). The XRD pattern of samples C5 and C6, synthesized from bentonite, showed also small reflection from the original bentonite. The interlayer space of the samples was analysed thorough a ${ }^{23} \mathrm{Na}$ MAS NMR spectroscopy (Fig. S2), and, in general, the spectra were characterized by three sets of signals: i) a main one in the range between 0 to -25 ppm that corresponds to the interlayer sodium (Laperche et al., 1990); ii) a narrow signal at ca. 5 ppm of sodalite (Johnson et al., 2000); and iii) a broad signal at ca. 27 ppm due to a non-exchangeable sodium (Zeng et al., 2013). The proportion of sodalite impurity was absent in sample C6, and was ca. $1 \%$ in samples $\mathrm{C} 1, \mathrm{C} 2$ and $\mathrm{C} 5$ and ca. $2 \%$ in sample $\mathrm{C} 3$ and $\mathrm{C} 4$. In all the cases, the proportion of the non-exchangeable cation was below $2.5 \%$. As state in the literature, the position of the ${ }^{23} \mathrm{Na}$ signal of the interlayer cation shifts towards higher frequency as higher hydration state (Casal et al., 1994; Laperche et al., 1990). The position of the signal, except for sample C3, was at ca. - $7.5 \mathrm{ppm}$ due to the one-layer hydrated interlayer sodium (Laperche et al., 1990). The signal of samples C4-C6 showed asymmetry at higher frequency which was interpreted as $\mathrm{Na}^{+}$coordinated by basal oxygens of the silicate sheet (Casal et al., 1994). The 
signal of sample C3 was at $-12 \mathrm{ppm}$, which was compatible with a less hydrated state of the interlayer sodium.

Fig. 5 shows the IRFT spectra of the clay minerals used as starting material and its evolution after the synthesis procedure. The IRFT spectra of kaolinites shows in the 4000$2500 \mathrm{~cm}^{-1}$ region four hydroxyl-stretching bands at $3695,3668,3650 \mathrm{~cm}^{-1}$ attributed to the hydroxyl-stretching modes of the inner surface hydroxyls and at $3619 \mathrm{~cm}^{-1}$ assigned to the inner hydroxyls (Frost et al., 2002). Talc and bentonite also show their characteristic hydroxyl-stretching bands at $3676 \mathrm{~cm}^{-1}$ for talc (Palaniandy and Azizli, 2009) and at ca. 3630 $\mathrm{cm}^{-1}$ for bentonites (Liu et al., 2011). Additionally, FTIR spectra of bentonites show vibration bands at $3525-3444 \mathrm{~cm}^{-1}$ due to water hydroxyl bound via hydrogen bonds, and at ca. 3315 $\mathrm{cm}^{-1}$ from free water (Liu et al., 2011). All those $\mathrm{OH}$ stretching bands disappear in samples C1-C6 and the two vibration bands from water hydroxyl are observed and they are typical of Na-Mica-4 (sample A2) which is a hydrated fluoromica.

In the $1350-750 \mathrm{~cm}^{-1}$ region, they exhibit in-plane $\mathrm{Si}-\mathrm{O}-\mathrm{Si}$ stretching vibrations, strong bands at 1037-1033 $\mathrm{cm}^{-1}$ and $1012-1002 \mathrm{~cm}^{-1}$, and an in-plane stretching band of apical Si-O bonds at ca. $1100 \mathrm{~cm}^{-1}$. The $\mathrm{Al}_{2} \mathrm{OH}$ bending bands near 915 and $935 \mathrm{~cm}^{-1}$ arise from vibrations of inner and inner-surface $\mathrm{OH}$ groups, respectively (Gates et al., 2017). The FTIR spectra of C1-C3 samples do not show those Si-O-Si stretching vibration bands of kaolinite but they show the Si-O-Si stretching band characteristic of Na-Mica-4 (sample A2) that shifts to lower frequency due to the substitution of Al for Si (Gates et al., 2017).

The evolution of $\mathrm{Al}$ and $\mathrm{Si}$ from the starting phyllosilicates to the synthetic mica was followed by the analysis of the ${ }^{27} \mathrm{Al}$ MAS-NMR (Fig. S4 and Fig. 3) and ${ }^{29}$ Si MAS-NMR spectra (Fig. S3 and Fig. 2). The ${ }^{27} \mathrm{Al}$ spectra of raw kaolinites (Fig. S4) show a main resonance at ca. $0 \mathrm{ppm}$ from the octahedral $\mathrm{Al}$ environment. The spectra of the original 
bentonites (Fig. S4) showed a main resonance at ca. 0 ppm, from the octahedral Al environment of dioctahedrical sheet of both bentonites (Engelhardt and Michel, 1987). Additionally, a small signal in the range $40-70$ ppm was observed, due to the tetrahedral coordinated Al (Engelhardt and Michel, 1987), which convolutes two signals: the main one at ca. $57 \mathrm{ppm}$ of $\mathrm{q}^{4}$ environment from impurities, and, a very small one at ca. $65 \mathrm{ppm}$ of the smectite $\mathrm{q}^{3}$ environment (Engelhardt and Michel, 1987). A similar spectrum to those of bentonite was exhibited by talc but with a very low $\mathrm{S} / \mathrm{N}$ ratio due to the low aluminium content in this sample. In all the cases, the ${ }^{27} \mathrm{Al}$ signals of the synthesis products (Fig. 3) were in the tetrahedral chemical shift range and with a quadrupolar lineshape typical of Na-Mica4, overlapping this signal a narrow signal of sodalite was observed (Naranjo et al., 2014).

The major component of the ${ }^{29} \mathrm{Si}$ MAS-NMR spectra (Fig. S3) for all the initial phyllosilicates corresponded to $\mathrm{Q}^{3}(0 \mathrm{Al})$ environments (Engelhardt and Michel, 1987). The differences observed in their chemical shifts were a consequence of their octahedral nature and their total layer charge values (Sanz and Serratosa, 1984). ${ }^{29}$ Si MAS-NMR spectra of the raw bentonites showed two sets of signals. The main one is in the range of -100 to $-80 \mathrm{ppm}$ from a smectite $\mathrm{Q}^{3}(\mathrm{mAl})$ environment, and the second one is in the range of -100 to -115 ppm from impurities $\mathrm{Q}^{4}(\mathrm{mAl})$ environment (Engelhardt and Michel, 1987). The synthesis products showed a main set of ${ }^{29} \mathrm{Si}$ signals (Fig. S3) on the -70 to $-95 \mathrm{ppm}$ region from the combination of $\mathrm{Q}^{3}(\mathrm{mAl})(3 \leq \mathrm{m} \leq 0)$ mica environments (Alba et al., 2006) and $\mathrm{Q}^{4}(4 \mathrm{Al})$ from sodalite (Johnson et al., 2000). The chemical shift of the all $\mathrm{Q}^{3}(\mathrm{mAl})(3 \leq \mathrm{m} \leq 0)$ environments was typical of Na-Mica-4 (Alba et al., 2006). The intensity of the distribution of the signal on sample C2 was similar to that of sample A2, however, in the rest of the samples, an enrichment of the $\mathrm{Q}^{3}(\mathrm{mAl})(\mathrm{m}>2)$ was observed, sample $\mathrm{C} 3$ being an exception and the most intense signal at $-75 \mathrm{ppm}$. The difference on intensity should only be due to a different 
tetrahedral sheet Al-Si distribution but not a decrease in the layer charge which would cause a shift to a lower frequency (Weiss et al., 1987). The only exception was sample C4 where two sets of signals described the spectrum and pointed out the presence of an inhomogeneous charge distribution. Finally, a narrow signal at ca. $-61.5 \mathrm{ppm}$ due to forsterite (Alba et al., 2006) was observed in samples C4-C6, which were synthesized from phyllosilicates with magnesium in the octahedral sheet.

Although hydrated Na-Mica-4 was synthetized from phyllosilicates, the purity of the final product and the $\mathrm{Si}-\mathrm{Al}$ distribution was affected by the nature of the phyllosilicates. Moreover, the facility of the starting clay minerals to be transformed to swelling highcharged micas depended on some structural characteristics: i) sheet stacking, 1:1 packing was more favourable than 2:1 (e.g. kaolinite vs bentonite); ii) octahedral occupancy, dioctahedral phyllosilicates provided best results than trioctahedral ones (e.g. bentonite vs talc). In a previous study, Alba et al. (Alba et al., 2010) observed that those structural characteristics were responsible of the destabilization of the phyllosilicates structure.

The comparison between $\mathrm{C} 1$ and $\mathrm{C} 2$ points out that higher defect concentration and higher external surface (Table S3) of the starting phyllosilicate favoured the formation of NaMica-4. The effect of defect concentration in synthesis starting materials was studied from the samples of series D, which were obtained after the mechanical milling of the kaolinites. The milling of the samples did not alter the structural order of kaolinites which exhibited similar ${ }^{29}$ Si MAS-NMR (Fig. S3), ${ }^{27}$ Al MAS-NMR (Fig. S4) and FTIR spectra (Fig. S5), but provoked the increasing of the external surface (Table S3) and it was equal for both kaolinite after the milling.

The samples synthesized from mechanical milled kaolinites (series D) had a XRD pattern compatible with that of hydrated Na-Mica-4 (Fig. 4) and with the ${ }^{23} \mathrm{Na}$ MAS NMR spectra 
characterized by a decreasing of the sodalite signal intensity, an increasing of the nonexchangeable sodium and an asymmetry to lower frequency of the interlayer sodium signal due to a lower hydration state. The milling did not affect the local order of aluminium (see ${ }^{27} \mathrm{Al}$ MAS NMR spectra, Fig. 3) or the chemical shift position of the ${ }^{29} \mathrm{Si}$ signals on the spectra (Fig. S3), however, an enrichment on $\mathrm{Q}^{3}(3 \mathrm{Al})$ was observed (Fig. 2).

\subsection{Effect of the heating.}

In this section, the effect of the crucible material (samples of series E) and the use of an open or closed crucible (samples of series F) were analysed (Table 1 and Table S2). The effect of temperature and time were not analysed because they were already evaluated, 900 ${ }^{\circ} \mathrm{C}$ during $15 \mathrm{~h}$ being the optimal conditions in Pt crucibles. (Alba et al., 2011; Naranjo et al., 2015)

The comparison of samples A2, E1 and E3 allowed the determination of the influence of the crucible material on synthesis products. The XRD patterns of the three samples were compatible with the presence of hydrated mica (Fig. 6) with the only difference of additional small reflections of sodalite in the sample synthesised with the $\mathrm{Al}_{2} \mathrm{O}_{3}$ crucible (sample E3). The ${ }^{23} \mathrm{Na}$ MAS NMR spectroscopy (Fig. S2) was used for the quantification of the sodalite impurity. The ${ }^{23} \mathrm{Na}$ MAS NMR spectra showed that in the three samples the main signal was centred at ca. -7.5 ppm which was compatible with one-layer hydrated interlayer sodium (Laperche et al., 1990). Additionally, a signal at ca. 5 ppm was observed in samples E1 and E3 that corresponded to sodalite (Naranjo et al., 2014) and involved the $0.7 \%$ and $3.4 \%$ of sodium, respectively. Finally, a signal at ca. 27 ppm (1.3\%) was observed in sample E3 due to a non-exchangeable sodium (Zeng et al., 2013). 
The effect of crucible materials in the framework atoms distribution was analysed thorough ${ }^{29} \mathrm{Si}$ and ${ }^{27} \mathrm{Al}$ MAS NMR spectroscopies (Fig. S6 and Fig. 3). The ${ }^{27} \mathrm{Al}$ MAS NMR spectra of samples E1 and E3 (Fig. 3) showed a main signal at ca. 65 ppm due to the majority of $\mathrm{Al}$ in a tetrahedral coordination (Naranjo et al., 2015) and an additional small signal at ca. $0 \mathrm{ppm}$ that was interpreted as aluminium in the octahedral sheet, as observed in the spectrum of A2. (Alba et al., 2006) However, in those samples the narrow and symmetric peak of sodalite (Naranjo et al., 2014) was observed with higher intensity in E3 than in E1 in accordance with the ${ }^{23} \mathrm{Na}$ MAS NMR data. The ${ }^{29} \mathrm{Si}$ MAS NMR spectra of E1 and E3 samples (Fig. S6) showed a set of signals in the same range of A2 and at the same chemical shift of Na-Mica-4. The only difference between those signal was the relative intensity of $\mathrm{Q}^{3}(\mathrm{mAl})$ of sample E1 (Fig. 2), an enrichment on the environment with $\mathrm{m}>3$ being observed. Additionally, the spectrum of sample E1 exhibited a signal of forsterite at ca. $\quad-61.5 \mathrm{ppm}$ (Thompson et al., 1993).

The analysis of the results indicated that swelling high-charged mica was produced independently from the crucible material, although the purity of the synthesis product decreased. In the case of $\mathrm{SiC}$ (sample E1), a small amount of sodalite and forsterite was observed. Whereas the $\mathrm{Si}: \mathrm{Al}$ stoichiometry of sodalite is $1: 1$ and should not affect the $\mathrm{Si}: \mathrm{Al}$ ratio of the final product, the $\mathrm{Si}: \mathrm{Al}$ proportion on forsterite is $1: 0$ and, thus, the $\mathrm{Si}$ environment with higher $\mathrm{Al}$ neighbouring should be favoured. However, the observed ${ }^{29} \mathrm{Si}$ MAS NMR data (Fig. 2) did not reflect it and an enrichment of Si environment was observed, probably due to a leaching of $\mathrm{Si}$ from the $\mathrm{SiC}$ crucible during the synthesis.

In the case of the $\mathrm{Al}_{2} \mathrm{O}_{3}$ crucible (sample E3), the only impurity was sodalite, which did not alter the Si/Al ratio as observed in the ${ }^{29} \mathrm{Si} \mathrm{MAS-NMR}$ spectra (Fig. 2). However, the high amount of sodalite should not be due to an optimized time of heating as previously 
observed by Alba et al. (Alba et al., 2011). The optimum reaction time for the $\mathrm{Al}_{2} \mathrm{O}_{3}$ crucible was tested thorough a set of synthesis performed at variable time (samples E2-E5). The XRD patterns (Fig. 6) were typical of the Na-Mica-4 for all the reaction times with a unique door of $12.1 \AA$, as expected for the hydrated interlayer cation, except for the shorter reaction time (sample E5) where a second small reflection was observed at $\mathrm{d}_{00 l}=9.5 \AA$ due to the dehydrated interlayer cation (Alba et al., 2006). Alba et al. (Alba et al., 2011) observed that full-hydrated mica in Pt crucible was only possible for time reaction $\geq 1 \mathrm{~h}$, however, in synthesis performed in $\mathrm{Al}_{2} \mathrm{O}_{3}$ crucible the mica remained partially dehydrated after $3 \mathrm{~h}$ of heating. In all the samples, sodalite reflections were observed and their intensity increased with the time reaction.

The ${ }^{23} \mathrm{Na}$ MAS-NMR spectra (Fig. S2) showed that the chemical shift of the main peak is at ca. $-7.5 \mathrm{ppm}$ compatible with one-layer hydrated interlayer sodium, (Laperche et al., 1990) but at $3 \mathrm{~h}$ the signal showed asymmetry at higher frequency, which was interpreted as $\mathrm{Na}^{+}$coordinated by basal oxygens of the silicate sheet (Casal et al., 1994). Additionally, a signal at ca. 5 ppm was observed due to sodalite (Johnson et al., 2000) and involved the 5.4 $\%, 3.4 \%, 1.5 \%$ and $2.4 \%$ of sodium, for E2-E5 respectively. Finally, a signal at ca. $27 \mathrm{ppm}$ was observed in samples E2 (2.4\%) and E3 (1.3\%) due to non-exchangeable sodium (Zeng et al., 2013).

The ${ }^{27} \mathrm{Al}$ MAS NMR spectra (Fig. 3) showed a main signal at ca. $65 \mathrm{ppm}$ due to the majority of Al in a tetrahedral coordination (Engelhardt and Michel, 1987); the additional small signal at ca. 0 ppm was also observed. The ${ }^{27} \mathrm{Al}$ signal due to sodalite was observed in all samples and with an intensity compatible with the ${ }^{23} \mathrm{Na}$ MAS NMR spectra.

The ${ }^{29}$ Si MAS NMR spectra of samples E2-E4 (Fig. S6 and Fig. 2) showed a set of signals at the same chemical shift and relative intensity of Na-Mica-4. The spectrum of 
sample E5 exhibited the same number of peaks but with two main differences: the signals shifted to lower frequency and the relative intensity of $\mathrm{Q}^{3}(\mathrm{mAl})$ with $\mathrm{m}>2$ increased. The observed relative intensity of the ${ }^{29} \mathrm{Si}$ signals in E5 indicated that a time reaction as low as 3 h, the layer charge of the mica was lower than 4 (Alba et al., 2006). The lower layer charge and the partial interaction of the interlayer $\mathrm{Na}^{+}$with the basal oxygens were responsible of the low frequency shift of the signals (Pavon et al., 2014a).

The observed difference on the time reaction between $\mathrm{Pt}$ and $\mathrm{Al}_{2} \mathrm{O}_{3}$ was compatible with their thermal conductivity.

The other factor to be taken into account is the use of an open or closed crucible (series F) during the heating. Fig. 7 showed the XRD patterns of both experiments and regardless of the use of cap, the final product was a pure hydrated Na-Mica-4. The hydrated state of interlayer $\mathrm{Na}^{+}$was also evident by ${ }^{23} \mathrm{Na}$ MAS NMR spectroscopy (Fig. S2).

At the synthesis temperature, fluorine could volatilize and affect the stoichiometric reaction, thus, both ${ }^{19} \mathrm{~F}$ MAS NMR and ${ }^{1} \mathrm{H}$ MAS NMR spectra were registered (Fig. S7). The ${ }^{19}$ F MAS NMR spectra were characterized by an intense peak at $-171.6 \mathrm{ppm}$, due to fluorine in an Mg-Mg-Mg environment (Reinholdt et al., 2005), and a small one at -147.0 ppm, due to a fluorocomplex $\mathrm{AlF}_{\mathrm{x}} \mathrm{OH}_{\mathrm{y}} \cdot \mathrm{zH}_{2} \mathrm{O}$ (Huve et al., 1992). The only difference was a small decrease in intensity of the main signal for the sample F2. The ${ }^{1} \mathrm{H}$ MAS NMR spectra exhibited a wide resonance at ca- 5 ppm due to hydration water of the interlayer sodium (Alba et al., 2003). The effect of the partial volatilization of fluorine on the mica framework was analysed by ${ }^{29} \mathrm{Si}$ MAS NMR (Fig. S6 and Fig. 2) and ${ }^{27} \mathrm{Al}$ MAS NMR (Fig. 3) spectroscopies. Both Si and Al heteroatoms showed an environment similar to hydrated NaMica-4 (sample A2). Therefore, the partial volatilization of fluorine when the synthesis was 
performed in an open crucible did not affect the mica structure at long or short range due to an excess of fluorine in the starting reaction mixture.

\subsection{Effect of washing.}

Water scarcity is a worldwide problem, thus, for a sustainable synthesis it is crucial to analyse the influence of the quantity and quality of water used in the final step of the synthesis, samples of series G, (Table 1 and Table S2).

The X-ray diffractograms of the samples of series G (Fig. 7) showed patterns similar to those of sample A2 and, thus, compatible with pure Na-Mica-4 (Alba et al., 2006). The unique 001 reflection corresponded to a basal space of $12.1 \AA$ and it indicated that the reduction of the water:solid proportion by a factor of 5 did not affect either the swelling of the layers or the quality of the water. A similar coordination sphere of interlayer $\mathrm{Na}^{+}$was corroborated by ${ }^{23} \mathrm{Na}$ MAS NMR spectra (Fig. S2) and, thus, changes in the framework of mica could not be expected. Only in the case of sample G2, an additional shoulder at ca. 5 ppm was observed due to sodalite (Johnson et al., 2000) and involved $0.2 \%$ of sodium. Both, the ${ }^{27} \mathrm{Al}$ MAS NMR (Fig. 3) and the ${ }^{29}$ Si MAS NMR spectra, (Fig. S8) and Fig. 2) showed similar sets of signals at similar position independently of the water amount and water quality used in the last step of the synthesis.

\section{Conclusions}

A deep analysis of all parameters that control the synthesis of this swelling high-charge mica has allowed shedding a light on the main factors that influence the design of the final product. 
The deficiency of $\mathrm{Al}$ and $\mathrm{Mg}$ in the mixture does not affect the formation of Na-Mica4 although a small amount of sodalite was formed. Moreover, milling the mixture in a ball mill or in an agate mortar does not affect the final product. However, the use of a ball mill allows synthesizing a higher amount of mica.

It has been possible to synthesize Na-Mica-4 from any natural clay, although the purity degree of the mica depends on the nature of those clay minerals. The ball mill grinding of the natural clays favored the formation of an $\mathrm{Q}^{3}(3 \mathrm{Al})$ environment.

The use of cheaper crucibles such as $\mathrm{SiC}$ or $\mathrm{Al}_{2} \mathrm{O}_{3}$ allowed the synthesis of Na-Mica4, although the calcination time should be tuned.

Finally, the quality and quantity of water is not crucial for pure Na-Mica-4 synthesis, which implies that a friendly environmental synthesis should be possible.

\section{Acknowledgements.}

We are grateful to the Junta de Andalucía (Spain) and FEDER for the project P12FQM-567 (Proyecto de Excelencia de la Junta de Andalucía), to the Spanish State Program $\mathrm{R}+\mathrm{D}+\mathrm{I}$ oriented societal challenges and FEDER (Project MAT2015-63929-R) and ENRESA (contract $n^{\circ}$ 0079000237) for financial support. Dr. Pavón thanks to Andalucía Talent Hub Program, co-funded by the EU in 7FP, Marie Skłodowska-Curie actions for the grant $\mathrm{n}^{\mathrm{o}}$ 291780. F.J. Osuna thanks his grant to the training researcher program associated to the Junta de Andalucía excellence project P12-FQM-567.

\section{Appendix A. Supplementary data}

Supplementary data can be found in the online version of the article 


\section{References}

Alba, M.D., Becerro, A.I., Castro, M.A., Perdigon, A.C., Trillo, J.M., 2003. Inherent acidity of aqua metal ions in solids: An assay in layered aluminosilicates. J. Phys. Chem. B 107(17), 3996-4001.

Alba, M.D., Castro, M.A., Chain, P., Orta, M.M., Pazos, M.C., Pavon, E., 2010. Hydrothermal stability of layered silicates in neutral and acidic media: Effect on engineered-barrier safety. Clay Clay Min. 58(4), 501-514.

Alba, M.D., Castro, M.A., Naranjo, M., Orta, M.M., Pavon, E., Pazos, M.C., 2011. Evolution of Phases and Al-Si Distribution during Na-4-Mica Synthesis. J. Phys. Chem. C 115(41), 20084-20090.

Alba, M.D., Castro, M.A., Naranjo, M., Pavon, E., 2006. Hydrothermal reactivity of Na-nmicas $(\mathrm{n}=2,3,4)$. Chem. Mat. 18(12), 2867-2872.

Bell, R.G., Jackson, R.A., Catlow, C.R.A., 1992. Lowenstein rule in zeolite-a - a computational study. Zeolites 12(7), 870-871.

Casal, B., Aranda, P., Sanz, J., Ruizhitzky, E., 1994. Interlayer adsorption of macrocycliccompounds (crown-ethers and cryptands) in 2/1 phyllosilicates .2. Structural features. Clay Min. 29(2), 191-203.

Engelhardt, G., Michel, D., 1987. High-Resolution Solid-State NMR of Silicates and Zeolites. John Wiley \& Sons, New York.

Frost, R.L., Mako, E., Kristof, J., Kloprogge, J.T., 2002. Modification of kaolinite surfaces through mechanochemical treatment - a mid-IR and near-IR spectroscopic study. Spectroc. Acta Pt. A-Molec. Biomolec. Spectr. 58(13), 2849-2859.

Gates, W.P., Kloprodgge, J.T., Madejová, J., Bergaya, F., 2017. Infrared and Raman spectroscopies of clay minerals. Elsevier, Netherlands. 
Gregorkiewitz, M., Rausellcolom, J.A., 1987. Characterization and properties of a new synthetic silicate with highly charged mica-type layers. Am. Miner. 72(5-6), 515-527.

Huve, L., Delmotte, L., Martin, P., Ledred, R., Baron, J., Saehr, D., 1992. F-19 mas-nmr study of structural fluorine in some natural and synthetic 2/1 layer silicates. Clay Clay Min. 40(2), 186-191.

Johnson, G.M., Mead, P.J., Dann, S.E., Weller, M.T., 2000. Multinuclear MAS NMR studies of sodalitic framework materials. J. Phys. Chem. B 104(7), 1454-1463.

Kloprogge, J.T., Hickey, L., Frost, R.L., 1999. Infrared study of some synthetic saponites: Effect of $\mathrm{NH} 4 / \mathrm{Al}$ and $\mathrm{H} 2 \mathrm{O} /(\mathrm{Si}+\mathrm{Al})$ ratios during the crystallization. J. Mater. Sci. Lett. 18(17), 1401-1403.

Kodama, T., Komarneni, S., 1999. Alkali metal and alkaline earth metal ion exchange with Na-4-mica prepared by a new synthetic route from kaolinite. J. Mater. Chem. 9(10), $2475-2480$.

Laperche, V., Lambert, J.F., Prost, R., Fripiat, J.J., 1990. High-resolution solid-state nmr of exchangeable cations in the interlayer surface of a swelling mica ${ }^{23} \mathrm{Na},{ }^{111} \mathrm{Cd}$, and ${ }^{133}$ Cs vermiculites. J. Phys. Chem. 94(25), 8821-8831.

Liu, Z.R., Uddin, M.A., Sun, Z.X., 2011. FT-IR and XRD analysis of natural Na-bentonite and $\mathrm{Cu}(\mathrm{II})$-loaded Na-bentonite. Spectroc. Acta Pt. A-Molec. Biomolec. Spectr. 79(5), 1013-1016.

Morikawa, Y., Goto, T., Morooka, Y., Ikawa, T., 1982. Conversion of methanol over metalion exchanged forms of fluor tetra silisic mica. Chem. Lett.(10), 1667-1670.

Naranjo, M., Castro, M.A., Cota, A., Osuna, F.J., Pavon, E., Alba, M.D., 2015. Synthesis temperature effect on Na-Mica-4 crystallinity and heteroatom distribution. Microporous Mesoporous Mat. 204, 282-288. 
Naranjo, M., Castro, M.A., Cota, A., Pavon, E., Pazos, M.C., Alba, M.D., 2014. A new route of synthesis of Na-Mica-4 from sodalite. Microporous Mesoporous Mat. 186, 176180.

Osuna, F.J., Cota, A., Pavon, E., Pazos, M.C., Alba, M.D., 2017. Cs+ immobilization by designed micaceous adsorbent under subcritical conditions. Appl. Clay Sci. 143, 293299.

Palaniandy, S., Azizli, K.A.M., 2009. Mechanochemical effects on talc during fine grinding process in a jet mill. Int. J. Miner. Process. 92(1-2), 22-33.

Park, M., Lee, D.H., Choi, C.L., 2002a. Conversion of fly ash to swelling mica: A new approach for recycling fly ash. J. Porous Mat. 9(4), 291-298.

Park, M., Lee, D.H., Choi, C.L., Kim, S.S., Kim, K.S., Choi, J., 2002b. Pure Na-4-mica: Synthesis and characterization. Chem. Mat. 14(6), 2582-2589.

Paulus, W.J., Komarneni, S., Roy, R., 1992. Bulk synthesis and selective exchange of strontium ions in $\mathrm{Na}_{4} \mathrm{Mg}_{6} \mathrm{Al}_{4} \mathrm{Si}_{4} \mathrm{O}_{20} \mathrm{~F}_{4}$ mica. Nature 357(6379), 571-573.

Pavon, E., Alba, M.D., Castro, M.A., Cota, A., Osuna, F.J., Pazos, M.C., 2017. Effect of the crystal chemistry on the hydration mechanism of swelling micas. Geochim. Cosmochim. Acta 217, 231-239.

Pavon, E., Castro, M.A., Cota, A., Osuna, F.J., Pazos, M.C., Alba, M.D., 2014a. Interaction of Hydrated Cations with Mica-n (n=2, 3 and 4) Surface. J. Phys. Chem. C 118(4), 2115-2121.

Pavon, E., Osuna, F.J., Alba, M.D., Delevoye, L., 2014b. Direct evidence of Lowenstein's rule violation in swelling high-charge micas. Chem. Commun. 50(53), 6984-6986. 
Pazos, M.C., Castro, M.A., Cota, A., Osuna, F.J., Pavon, E., Alba, M.D., 2017. New insights into surface-functionalized swelling high charged micas: Their adsorption performance for non-ionic organic pollutants. J. Ind. Eng. Chem. 52, 179-186.

Reinholdt, M., Miehe-Brendle, J., Delmotte, L., Le Dred, R., Tuilier, M.H., 2005. Synthesis and characterization of montmorillonite-type phyllosilicates in a fluoride medium. Clay Min. 40(2), 177-190.

Sanz, J., Serratosa, J.M., 1984. Si-29 and Al-27 high-resolution MAS-NMR spectra of phyllosilicates. J. Am. Chem. Soc. 106(17), 4790-4793.

Thompson, J.G., Withers, R.L., Whittaker, A.K., Traill, R.M., Fitz Gerald, J.D., 1993. A reinvestigation of low-carnegieite by XRD, NMR, and TEM. J. Solid State Chem. 104(1), 59-73.

Weiss, C.A., Altaner, S.P., Kirkpatrick, R.J., 1987. High-resolution Si-29 NMRspectroscopy of 2-1 layer silicates - correlations among chemical-shift, structural distortions, and chemical variations. Am. Miner. 72(9-10), 935-942.

Zeng, Z., Matuschek, D., Studer, A., Schwickert, C., Pottgen, R., Eckert, H., 2013. Synthesis and characterization of inorganic-organic hybrid materials based on the intercalation of stable organic radicals into a fluoromica clay. Dalton Trans. 42(24), 8585-8596.

Zhang, D., Zhou, C.H., Lin, C.X., Tong, D.S., Yu, W.H., 2010. Synthesis of clay minerals. Appl. Clay Sci. 50(1), 1-11. 
Table 1.

Synthesis conditions

\begin{tabular}{|c|c|c|c|c|c|c|}
\hline & Precursor mixing & & & heating & & washing \\
\hline Samples & Chemical source & Stoichiometry & Mixing & $\begin{array}{l}\text { Crucible } \\
\text { material }\end{array}$ & $\begin{array}{l}\text { Crucible } \\
\text { cap }\end{array}$ & $\begin{array}{l}\text { volume } \\
(\mathrm{ml})\end{array}$ \\
\hline A1 & $\begin{array}{l}\text { Commercial oxides } \\
\text { and salts }\end{array}$ & Si:0.98Al:1.39Mg:2.02Na & agate & $\mathrm{Pt}$ & No & 100 \\
\hline A2 & $\begin{array}{l}\text { Commercial oxides } \\
\text { and salts }\end{array}$ & $\mathrm{Si}: \mathrm{Al}: 1.5 \mathrm{Mg}: 2 \mathrm{Na}$ & agate & $\mathrm{Pt}$ & No & 100 \\
\hline B1 & $\begin{array}{l}\text { Commercial oxides } \\
\text { and salts }\end{array}$ & $\mathrm{Si}: \mathrm{Al}: 1.5 \mathrm{Mg}: 2 \mathrm{Na}$ & agate & $\mathrm{Pt}$ & No & 100 \\
\hline $\mathrm{B} 2$ & $\begin{array}{l}\text { Commercial oxides } \\
\text { and salts }\end{array}$ & $\mathrm{Si}: \mathrm{Al}: 1.5 \mathrm{Mg}: 2 \mathrm{Na}$ & ball $^{\mathrm{a}}$ & $\mathrm{Pt}$ & No & 100 \\
\hline $\mathrm{C} 1$ & KGa-1b & Si:Al: $1.5 \mathrm{Mg}: 2 \mathrm{Na}$ & agate & $\mathrm{Pt}$ & No & 100 \\
\hline $\mathrm{C} 2$ & KGa-2 & $\mathrm{Si}: \mathrm{Al}: 1.5 \mathrm{Mg}: 2 \mathrm{Na}$ & agate & $\mathrm{Pt}$ & No & 100 \\
\hline $\mathrm{C} 3$ & Kaolinite Fluka & $\mathrm{Si}: \mathrm{Al}: 1.5 \mathrm{Mg}: 2 \mathrm{Na}$ & agate & $\mathrm{Pt}$ & No & 100 \\
\hline $\mathrm{C} 4$ & Talc & Si:Al: $1.5 \mathrm{Mg}: 2 \mathrm{Na}$ & agate & $\mathrm{Pt}$ & No & 100 \\
\hline C5 & Bentonite FEBEX & $\mathrm{Si}: \mathrm{Al}: 1.5 \mathrm{Mg}: 2 \mathrm{Na}$ & agate & $\mathrm{Pt}$ & No & 100 \\
\hline C6 & Bentonite MX80 & Si:Al:1.5Mg:2Na & agate & $\mathrm{Pt}$ & No & 100 \\
\hline D1 & KGa- $1 b^{b}$ & $\mathrm{Si}: \mathrm{Al}: 1.5 \mathrm{Mg}: 2 \mathrm{Na}$ & agate & $\mathrm{Pt}$ & No & 100 \\
\hline D2 & $\mathrm{KGa}-2^{\mathrm{b}}$ & $\mathrm{Si}: \mathrm{Al}: 1.5 \mathrm{Mg}: 2 \mathrm{Na}$ & agate & $\mathrm{Pt}$ & No & 100 \\
\hline E1 & $\begin{array}{l}\text { Commercial oxides } \\
\text { and salts }\end{array}$ & $\mathrm{Si}: \mathrm{Al}: 1.5 \mathrm{Mg}: 2 \mathrm{Na}$ & agate & $\mathrm{SiC}$ & No & 100 \\
\hline $\mathrm{E} 2$ & $\begin{array}{l}\text { Commercial oxides } \\
\text { and salts }\end{array}$ & $\mathrm{Si}: \mathrm{Al}: 1.5 \mathrm{Mg}: 2 \mathrm{Na}$ & agate & $\mathrm{Al}_{2} \mathrm{O}_{3}{ }^{\mathrm{c}}$ & No & 100 \\
\hline E3 & $\begin{array}{l}\text { Commercial oxides } \\
\text { and salts }\end{array}$ & Si:Al:1.5Mg:2Na & agate & $\mathrm{Al}_{2} \mathrm{O}_{3}$ & No & 100 \\
\hline E4 & $\begin{array}{l}\text { Commercial oxides } \\
\text { and salts }\end{array}$ & $\mathrm{Si}: \mathrm{Al}: 1.5 \mathrm{Mg}: 2 \mathrm{Na}$ & agate & $\mathrm{Al}_{2} \mathrm{O}_{3}{ }^{\mathrm{d}}$ & No & 100 \\
\hline E5 & $\begin{array}{l}\text { Commercial oxides } \\
\text { and salts }\end{array}$ & $\mathrm{Si}: \mathrm{Al}: 1.5 \mathrm{Mg}: 2 \mathrm{Na}$ & agate & $\mathrm{Al}_{2} \mathrm{O}_{3}{ }^{\mathrm{e}}$ & No & 100 \\
\hline $\mathrm{F} 1$ & $\begin{array}{l}\text { Commercial oxides } \\
\text { and salts }\end{array}$ & Si:Al:1.5Mg:2Na & agate & $\mathrm{Pt}$ & No & 100 \\
\hline F2 & $\begin{array}{l}\text { Commercial oxides } \\
\text { and salts }\end{array}$ & $\mathrm{Si}: \mathrm{Al}: 1.5 \mathrm{Mg}: 2 \mathrm{Na}$ & agate & $\mathrm{Pt}$ & Yes & 100 \\
\hline G1 & $\begin{array}{l}\text { Commercial oxides } \\
\text { and salts }\end{array}$ & $\mathrm{Si}: \mathrm{Al}: 1.5 \mathrm{Mg}: 2 \mathrm{Na}$ & agate & $\mathrm{Pt}$ & No & 20 \\
\hline $\mathrm{G} 2$ & $\begin{array}{l}\text { Commercial oxides } \\
\text { and salts }\end{array}$ & $\mathrm{Si}: \mathrm{Al}: 1.5 \mathrm{Mg}: 2 \mathrm{Na}$ & agate & $\mathrm{Pt}$ & No & $100^{\mathrm{f}}$ \\
\hline
\end{tabular}

${ }^{\text {a }}$ The mixed amount milled was double in B2 than in B1. In this serie, the hated amount of sample was double than in the rest of the series

before mixing the kaolinites were grinding in a ball grinder.

heating time: ${ }^{\mathrm{c}} 30 \mathrm{~h},{ }^{\mathrm{d}} 7.5 \mathrm{~h}$ and ${ }^{\mathrm{e}} 3.0 \mathrm{~h}$

${ }^{\mathrm{f}}$ washed with tap water 


\section{FIGURE CAPTIONS}

Fig. 1. XRD patterns of the samples of series A and B. s= sodalite (PDF 72-0029).

Fig. 2. ${ }^{29}$ Si MAS NMR environment distribution of the samples of series: a) A and B; b) C and D; c) E and F; and; d) G.

Fig. 3. ${ }^{27} \mathrm{Al}$ MAS NMR spectra of the samples of series: a) A and B; b) C and D; c) E and F; and; d) G.

Fig. 4. XRD patterns of the samples of series $C$ and D. The $C 3$ XRD pattern corresponds to dehydrated mica (PPF 00-054-1026).

Fig. 5. FTIR spectra series C samples. FTIR spectra of clay and Na-Mica-4 (sample A2) have been included as reference.

Fig. 6. XRD patterns of the samples of series E and F. s= sodalite (PDF 72-0029).

Fig. 7. XRD patterns of the samples of series G. 
Fig. 1

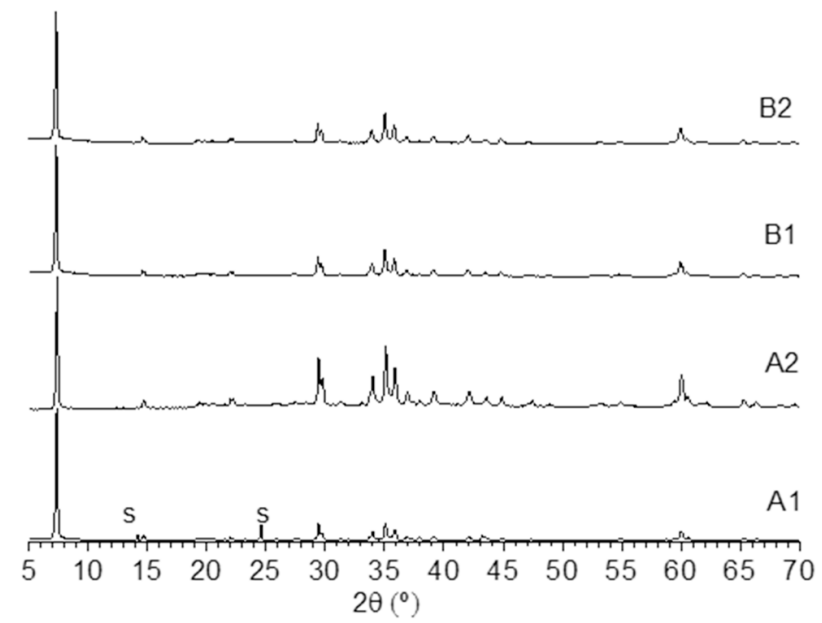


Fig. 2
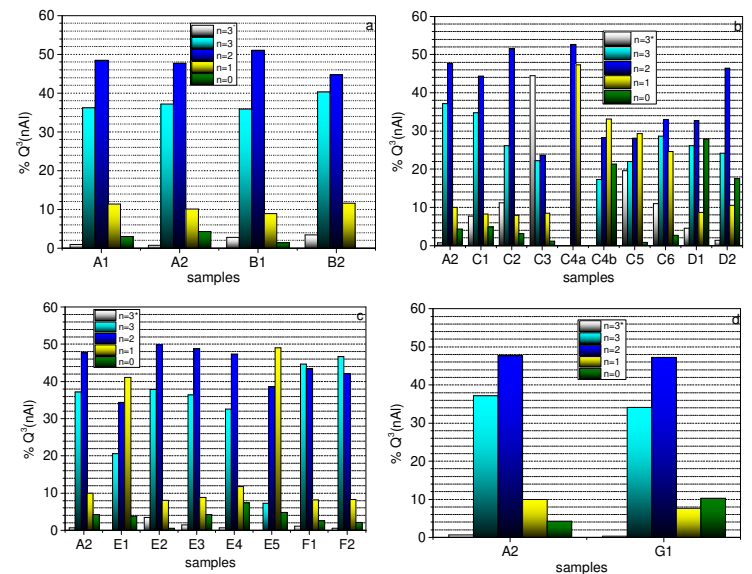
Fig. 3
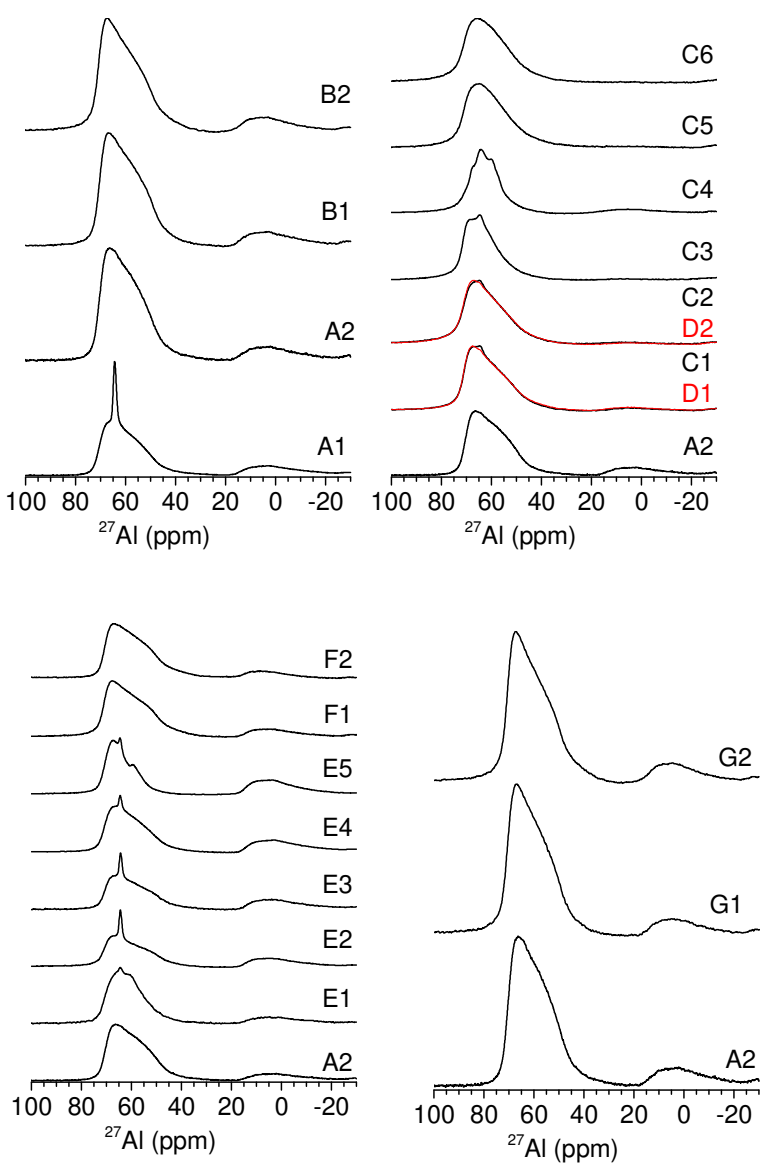
Fig. 4

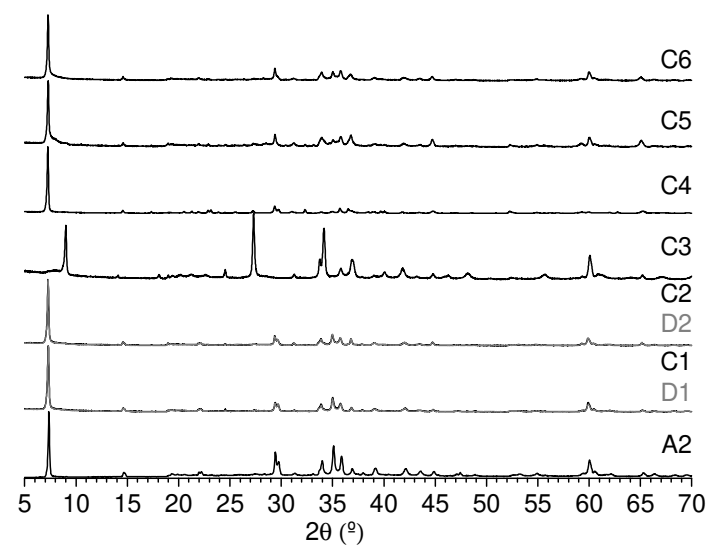


Fig. 5
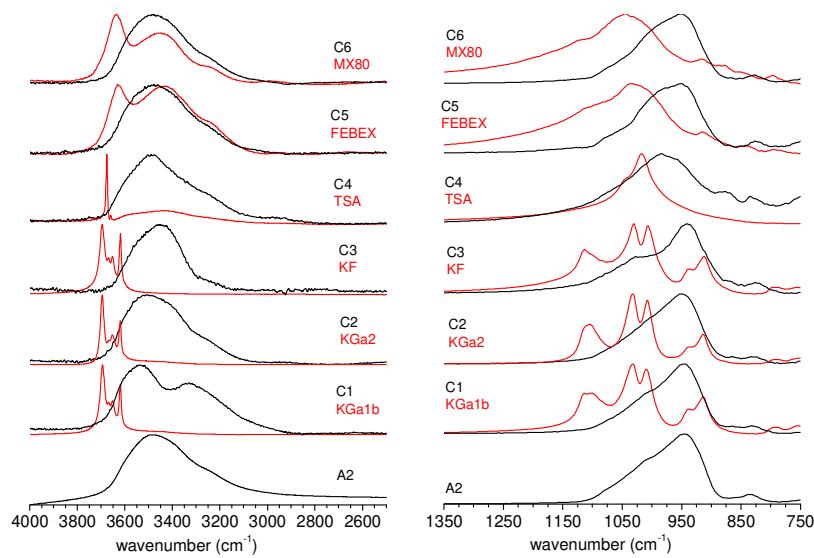
Fig. 6

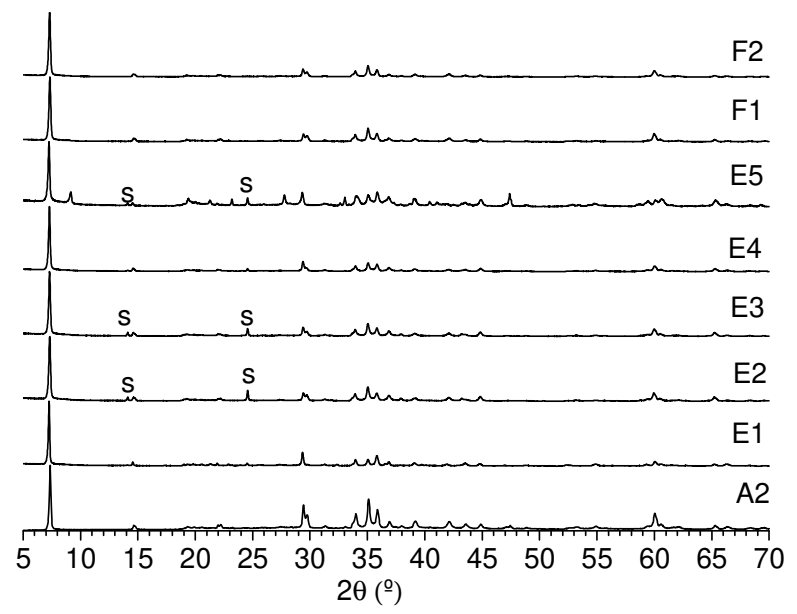


Fig. 7

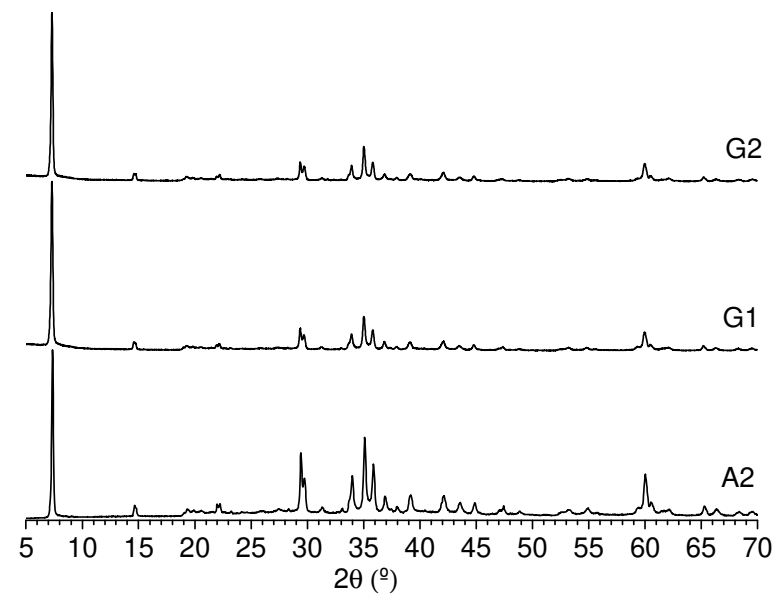




\section{Abstract Graphic}

\begin{tabular}{|c|c|c|c|c|}
\hline & & & & \\
\hline & Precursor mixing & Heating & Nashing & \begin{tabular}{|l|} 
Na-Mica-4 \\
\end{tabular} \\
\hline & $\sqrt{2}$ & 0.07 & & $\frac{m i n g}{M M}$ \\
\hline $\begin{array}{lllll}0 & 0 & 0 \\
0 & 0 & 0 & 0\end{array}$ & 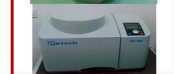 & & & $\frac{1}{1-14}$ \\
\hline
\end{tabular}

